\title{
PREMATURITY AND PAID WORK DURING PREGNANCY
}

\author{
BY \\ R. ILLSLEY AND W. Z. BILLEWICZ \\ Social Medicine Research Unit, Medical Research Council, \\ AND A. M. THOMSON \\ Department of Midwifery, University of Aberdeen
}

Most enquiries into the causes of prematurity conclude that at least 50 per cent. of cases cannot be explained on medical grounds (Joint Committee of the Royal College of Obstetricians and Gynaecologists and the British Paediatric Association, 1949; Baird, 1953). In these cases pregnancy is clinically normal but nevertheless labour starts before the expected date, or, if the baby is born at term, it weighs $5 \frac{1}{2} \mathrm{lb}$. or less. In such circumstances poor maternal health and physique, inadequate diet, and overwork or worry may be involved.

These influences are difficult to measure, and since several may operate together the effect of each cannot be easily disentangled. For example, hard physical work might have no ill effect on a healthy well-fed woman but might bring on premature labour in one who is under-nourished or unhealthy. Again it seems possible that paid work accompanied by heavy domestic responsibilities or anxieties over money or housing might cause more harm than the same amount of work done under happier conditions. Light work in an office, shop, or factory may not involve as much strain as housework and, if there is little domestic responsibility, may be more a relaxation than a task.

Various investigators have shown, however, that the prematurity rate increases with the length of time worked during pregnancy (Royal College of Obstetricians and Gynaecologists, 1948; Douglas, 1950; Ferguson and Logan, 1953). Our preliminary investigations pointed in the same direction. Table I shows that in Aberdeen in each social class married

TABLE 1

INCIDENCE (PER CENT.) OF PREMATURITY ACCORDING TO PERIOD OF WORK DURING PREGNANCY

\begin{tabular}{|c|c|c|c|c|c|}
\hline \multirow{2}{*}{\multicolumn{3}{|c|}{ Social Class }} & \multicolumn{2}{|c|}{ Weeks Worked } & \multirow{2}{*}{ Total } \\
\hline & & & Under 21 & 21 or more & \\
\hline $\begin{array}{l}\text { I, II } \ldots \\
\text { III }_{\text {IV, V }}\end{array}$ & $\begin{array}{l}\ldots \\
\cdots\end{array}$ & $\begin{array}{l}\ldots \\
\cdots\end{array}$ & $\begin{array}{l}3 \cdot 6(83) \\
4 \cdot 4(181) \\
7 \cdot 6(119)\end{array}$ & $\begin{array}{l}10.0(20) \\
13.9(72) \\
10.6(94)\end{array}$ & $\begin{array}{l}4 \cdot 9(103) \\
7 \cdot 1(253) \\
8 \cdot 9(213)\end{array}$ \\
\hline
\end{tabular}

Numbers of cases are given in brackets. primiparae who worked beyond the 20th week of pregnancy had a higher rate of prematurity than those who stopped earlier. Social classification is based on the husband's occupation (General Register Office, 1951).

It cannot, however, be inferred from this association that there is a causal relationship between the duration of paid work and prematurity. Women who work during pregnancy may do so because they need money, and their living standards and standards of health may be low. These circumstances, rather than the work itself, may be the cause of prematurity. Indeed, paid work might be beneficial, since the money earned could be used to improve living standards.

The problems of mothers with several children are very different from those of primigravidae. They have a more settled home background, and, although they do not usually undertake full-time employment outside the home, have heavy household duties which impose a greater physical and mental strain than most outside work. Fortunately, the physiological processes of reproduction are usually at their most efficient during the second, third, and fourth pregnancies, and this fact, rather than less work, paid or unpaid, probably explains why, in Aberdeen, multigravidae were found to have a lower incidence of prematurity than primigravidae.

In this inquiry, a group of primigravidae where pregnancy ended in the birth of a baby weighing $5 \frac{1}{2} \mathrm{lb}$. or less was compared with a matched control group where the babies weighed $6 \frac{1}{2} \mathrm{lb}$. to $8 \frac{1}{2} \mathrm{lb}$. If duration of paid work during pregnancy were a causal influence in prematurity, the former group should contain more women who worked late in pregnancy than the latter.

\section{Plan of THE ENQUiRy}

1. Population Studied.-It was decided to limit the inquiry to 1,750 legitimate single births to primiparae resident in the city of Aberdeen and delivered in the Aberdeen Maternity Hospital as booked cases during 
1952 and 1953. These constituted 90 per cent. of all legitimate first births in the city during the 2 years and provided for study 136 babies weighing $5 \frac{1}{2} \mathrm{lb}$. or less.

It was decided to omit from further consideration 27 cases in which there was an obvious clinical explanation of the prematurity. These omissions comprised:

Seventeen cases where labour had been induced by rupture of the membranes before the 39th week of pregnancy;

Five in which the foetus was seriously deformed;

Five in which the mother suffered from a chronic disease incidental to the pregnancy but likely to be the cause of the prematurity.

Thus 109 cases of prematurity remained for study; in these, the mothers did not suffer from serious incidental disease, the babies had no serious deformity, and labour began spontaneously or pregnancy was allowed to continue until at least the 39 th week.

In order to increase the contrast between the premature and non-premature groups, 373 cases in which the babies weighed between $5 \frac{1}{2}$ and $6 \frac{1}{2} \mathrm{lb}$. were excluded from the controls; 136 babies over $8 \frac{1}{2} \mathrm{lb}$. were also omitted because excessive birth weight may be associated with abnormality in the mother or child, e.g. diabetes. Fourteen cases showing abnormalities similar to those in the 27 omitted cases of prematurity were also excluded from the controls. Thus 1,091 out of the 1,614 cases in which the baby weighed more than $5 \frac{1}{2} \mathrm{lb}$. were available for selection of the matched controls.

2. Matching Procedure.-In inquiries which relate medical phenomena to social conditions it is usual to analyse the results for each social class separately so that the effect of any special influence, e.g. work, can be studied in the context of broadly similar social conditions. Since no known method of classification can produce groups with homogeneous social and economic characteristics this method is rather crude.

An analysis of data for the married primiparae resident in Aberdeen who were booked at the maternity hospital showed that women in the poorer social classes, women of short stature, and women aged 15-19 at the time of delivery were more likely to work during the second half of pregnancy. Many patients who worked late in pregnancy had conceived before marriage, and thus had an incentive to continue earning money to meet the costs of marriage and parenthood. On the other hand they had few domestic responsibilities during early pregnancy, and being unable to find independent accommodation after marriage, the majority lived with their husbands as boarders in the parental home. Where pregnancy occurs before marriage, women tend to postpone their first visit to the antenatal clinic until after marriage and thus as a group they have less antenatal care than usual. Social class, growth, duration of marriage, age at delivery, work during pregnancy, housing conditions, and antenatal attendance at clinics are all inter-related. Social classification by itself does not sufficiently control all the variables other than work in pregnancy which it is desired to eliminate from consideration.

In selecting the control group it was decided to match for social class, height, age, timing of marriage, and type of work done during or before pregnancy. Whilst prematurity might also be affected by the duration of antenatal care and by the physical strain imposed by different types of housing conditions and domestic responsibilities, the groups were not matched in those two respects as it was considered that groups matched in the way already mentioned would have very similar antenatal care and housing conditions. The date at which women stopped work, which was obtained from independent sources, was not known at the time of matching.

The matching criteria were classified as follows:

Husband's Social Class I, II; III; IV, V.

Wife's Main Occupation Professional and technical; clerical; shop assistant; skilled manual; semi-skilled and unskilled manual.

Age at Delivery $15-19 ; 20-29 ; 30$ and over. Height Under 5ft. 1in.;5ft. 1in.-5ft. 3in; $5 \mathrm{ft} .4 \mathrm{in}$. and over.

Timing of Marriage Pre-marital conception; postmarital conception.

For each premature case one control was chosen of the same social class and occupational group, and the same age, height, and marriage/conception group. There was usually a choice of controls, and the case with the nearest hospital admission number was selected.

When the date of stopping work came to be determined, it was found that out of the 109 prematures and their controls information was not available for three premature and two control cases and these were rejected together with their opposite numbers. The week of pregnancy at which the women stopped work was then calculated from the beginning of the last menstrual period, as established by the senior medical staff of the Aberdeen Maternity Hospital during their routine care of the patients. One premature case was rejected together with its control, as the date of the last menstrual period could not be estimated sufficiently accurately, thus leaving a total of 103 premature and 103 control cases.

\section{RESULTS}

If prolonged work during pregnancy were a cause of prematurity we would expect to find that more premature cases than controls worked to a late stage of pregnancy. As will be seen from Table II the two groups were closely similar in the duration of work.

As already stated, cases of serious abnormality of pregnancy leading to early obstetrical intervention, and cases of serious foetal and maternal abnormality, were excluded, but the premature group still contained a number of cases where pregnancy was complicated by such clinical abnormalities as pyelitis, threatened abortion, ante-partum haemorrhage, or pre-eclampsia. Some of these abnormalities might have been responsible for the occurrence of prematurity, and they might also have caused the patient to stop work. These cases were therefore separated out, leaving a group of 64 cases in which, apart from the birth of a premature baby, the course 
of pregnancy was uneventful. The analysis was repeated using this group of "normal pregnancies". Some of the matched controls for this group were not clinically normal since the matching procedure had not taken clinical phenomena into consideration, and one might therefore expect to find a shorter duration of work in the control cases; but as shown in Table II there is very little difference between the groups.

TABLE II

DURATION OF WORK IN PREMATURE AND CONTROL GROUPS

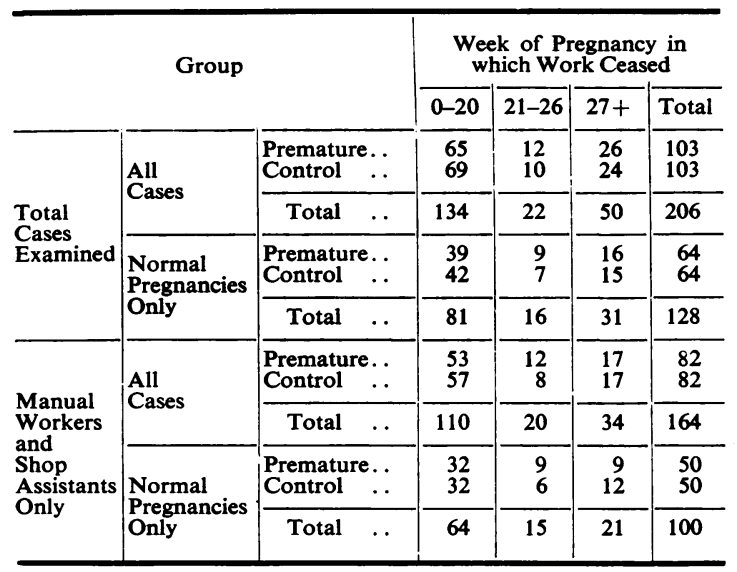

Since manual work might impose a greater strain than non-manual work, and might hence be deleterious, the analysis was repeated for shop assistants and manual workers only. Again there was no difference in the duration of work between the premature and control groups.

As already stated the premature and control groups were not matched for duration of antenatal care or for housing conditions. While the investigation was not primarily concerned with these matters, the two groups were in fact almost identical in respect of the stage of pregnancy at which patients first reported to the antenatal clinic. Data taken from the Almoners' records showed that 60 per cent. of the premature group had modern conveniences at home (fixed bath, piped hot water, and inside W.C.) compared with 53 per cent. of the control group. The domestic responsibilities of each woman are noted routinely by the Almoners and classified according to whether the patient has full or partial responsibility for the management of her home, or whether she and her husband are boarding with another family. The numbers with partial responsibility were equal in each group, but the premature group contained more women with full responsibility (33 against 25 in the control group) and fewer women who were boarding (30 against 38 ). Further inspection showed that the women with full domestic responsibility in the premature group gave up work at an earlier stage than women with full responsibility in the control group. If the greater domestic responsibility is set against the shorter duration of outside work, then there is probably no substantial difference between the two groups in the total work output.

\section{CONCLUSION}

This investigation is based on a small number of cases, but the similar duration of work in the premature and control groups is striking and repeats itself consistently for sub-groups such as manual workers, or women with clinically normal pregnancies where the closest association between duration of work and "unexplained" prematurity might be expected. Though women who work until a late stage of pregnancy are more likely to have premature babies, there is no evidence that increased length of work, by itself, predisposes to prematurity. The amount of antenatal care and of domestic responsibility and the nature of housing conditions also seem to have little direct effect on prematurity rates.

Yet the social gradient in the incidence of prematurity is pronounced, and has been widely reported. This probably arises because living conditions which produce well-grown and healthy mothers lead also to a low prematurity rate (Baird, 1953; Baird and Illsley, 1953). "A healthy way of life" is composed of many different influences. Thus, it is probably unrealistic to expect any single social factor, such as paid work during pregnancy, housing conditions, or antenatal care, to exercise a predominant influence on prematurity. The type of mother is more important than the conditions under which her pregnancy is carried through.

The limitations of this study must be stressed. It does not show that the amount of physical strain experienced by the individual mother during pregnancy is unimportant; nor does it show whether type or duration of work has any influence on the production of abnormalities of pregnancy, which in turn may give rise to prematurity.

The results of this investigation do not in any way impair the clinical principle that the patient who appears to be suffering from physical strain should rest; but they do suggest that further social measures designed to reduce the duration of paid work undertaken by primigravidae would do little to lower the incidence of prematurity. 


\section{SUMMARY}

(1) 103 primiparae who gave birth to premature babies (birth weight $5 \frac{1}{2} \mathbf{l b}$. or less) were compared with 103 matched primiparae whose babies weighed $6+8 \frac{1}{2} \mathrm{lb}$. Cases in each group were matched in pairs for a number of factors known to be associated with prematurity or with duration of work in pregnancy, namely: husband's social class; wife's occupation; age at delivery; maternal height; whether conception was pre-marital or post-marital.

(2) When the groups were matched thus, they showed little or no difference in average duration of antenatal care, in housing conditions, or in domestic responsibility.

(3) No difference was found between the groups in respect of duration of paid work during pregnancy.
This held good when cases of clinically normal pregriancy were considered separately; it was also true for women who were manual workers and shop assistants.

We are grateful for advice and criticism to Professor D. Baird, Department of Midwifery, Aberdeen, and Dr. J. N. Morris and Mr. J. A. Heady of the Social Medicine Research Unit, Medical Research Council.

\section{REFERENCES}

Baird, D. (1953). Proc roy. Soc. Med., 46, 877.

and Illsley, R. (1953). Ibid., 46, 53.

Douglas, J. W. B. (1950). J. Obstet, Gynaec. Brit. Emp., 57, 143.

Ferguson, T., and Logan, J. C. (1953). Glasg. med. J., 34, 221.

General Register Office. (1951). "Classification of Occupations, 1950". H.M.S.O., London.

Joint Committee of the Royal College of Obstetricians and Gynaecologists and the British Paediatric Association (1949). "Neonatal Mortality and Morbidity". Ministry of Health. Reports on Public Health and Medical Subjects, No. 94. H.M.S.O., London.

Royal College of Obstetricians and Gynaecologists and Population Investigation Committee (1948). "Maternity in Great Britain". Oxford University Press, London. 